OPTICAL PROPERTIES OF $\left[\left(\mathrm{TeO}_{2}\right)_{0.7}\left(\mathrm{~B}_{2} \mathrm{O}_{3}\right)_{0.3}\right]_{100-\mathrm{x}}(\mathrm{BaO})_{\mathrm{x}}$ GLASS SYSTEM

\title{
Ghada Adel
}

Physics Department, Faculty of Science, Al-Azher University, Nasr City, Cairo, Egypt.

\begin{abstract}
The physical and optical properties of glasses having a composition $\left[\left(\mathrm{TeO}_{2}\right)_{0.7}\left(\mathrm{~B}_{2} \mathrm{O}_{3}\right)_{0.3}\right]_{100-x}(\mathrm{BaO})_{x}$, where $(x=50,60,70)$ have been studied. It was found that the values of density increase by increasing BaO content while as the values of molar volume and oxygen packing density decrease for all the studied samples. Also, it was found that the values of the optical energy gap decrease while as the values of the refractive index increase by increasing $\mathrm{BaO}$ content. The optical basicity of the glasses and the polarizability of oxide ions have been calculated. It has been found that all the studied glasses become more polarized and more basic and the entire studied samples exhibit insulating behavior by increasing BaO content. Finally, all the prepared samples have higher values of third order nonlinear susceptibility (5.361-9.635) $x 10^{-12}$ esu; this means that all the studied samples are possibly good materials for nonlinear optical requests.
\end{abstract}

Keywords: Density, molar volume, optical basicity, polarizability of oxide ions, metallization, optical energy gap, refractive index and third order nonlinear susceptibility.

\section{INTRODUCTION}

The optical energy gap and the refractive index are the most interesting and fundamental properties of glass materials. Glasses with higher refractive indices are expected to have higher third order nonlinear susceptibility values [1, 2]. It was found that telluride glasses possess high optical nonlinearity and have possible application as nonlinear optical materials [3]. The structure and optical properties of telluride glasses have been studied [4,5]. Borate glasses have been attracted attention due to their practical applications in the fields of linear and nonlinear optics and correlated techniques [6]. It was found [7] that barium-borate glasses have good value in mass attenuation coefficient and effective atomic number which make good radiation shielding materials. $\left(\mathrm{B}_{2} \mathrm{O}_{3} \mathrm{TeO}_{2}\right)$ glasses have been shown progressive changes in both the boron and tellurium coordination with the addition of other ions $[8,9]$. The aim of the present work is to study, the physical and optical properties of $\left[\left(\mathrm{TeO}_{2}\right)_{0.7}\left(\mathrm{~B}_{2} \mathrm{O}_{3}\right)_{0.3}\right]_{100-\mathrm{x}}(\mathrm{BaO})_{\mathrm{x}}(\mathrm{x}=50,60,70)$ in order to show the effect of chemical modifier such as $\mathrm{BaO}$ on physical and optical properties when added to $\left(\mathrm{B}_{2} \mathrm{O}_{3} \mathrm{TeO}_{2}\right)$ glasses.

\section{EXPERIMENTAL DETAILS:}

Proper weights of $\mathrm{B}_{2} \mathrm{O}_{3}, \mathrm{TeO}_{2}$ and $\mathrm{BaO}$ in accurate molar ratio were mixed to obtain uniform acceptable fine powder and then, placed in a porcelain crucible and heated in an electric furnace whose temperature was elevated in steps to $1100^{\circ} \mathrm{C}$ for half an hour. Then, the molten samples were rapidly decreased to room temperature by pouring it onto a cooper plate and successively pressing it with another to gain glasses. The studied samples have been characterized by the X-ray diffraction (XRD) and all the samples reveal non-crystalline nature as so noticeable peak was detected in their (XRD). The transmissions of all the samples in the wave length (400-1100nm) were measured using a computerized recording spectrophotometer (type Jacob, V-570).

\section{RESULTS AND DISCUSSIONS:}

\subsection{Density and molar volume:}

The density of the samples was calculated using this equation:

$$
\mathrm{d}=0.8635\left[\mathrm{~W}_{\mathrm{a}} /\left(\mathrm{W}_{\mathrm{a}}-\mathrm{W}_{\mathrm{b}}\right)\right]
$$

Where, $d$ is the density of the glass sample, $\mathrm{W}_{\mathrm{a}}$ is the weight of the glass sample in air, $\mathrm{W}_{\mathrm{b}}$ is the weight of the glass sample in toluene and 0.8635 is the density of toluene. The values of density for all the studied samples are listed in table (1). The molar volume $\mathrm{V}_{\mathrm{m}}$ can be calculated as following, 
The molar volume =

(Total molecular weight)/ (density)

The values of molar volume for all the studied samples are listed in table (1).Oxygen packing density is the decoration of the oxygen atoms in the glass system and can be calculated as follows,

\section{Oxygen packing density $=(1000 \times 0) / V_{m}$}

Where, $\mathrm{O}$ denotes the sum of oxygen in the oxide glass element. It is clear that the values of the density become higher because the values of molecular weight increase by increasing $\mathrm{BaO}$ content for all the studied samples .Usually, the density of the glass changes in the inverse direction of the molar volume. It was found that the values of molar volume decrease by increasing $\mathrm{BaO}$ content for all the studied samples. The reduction in the oxygen packing density is most likely due to the decrease in number of oxygen atoms molecule.

\subsection{The optical basicity:}

The optical basicity, addresses the ability of oxide glass in contributing the negative charges in the glass matrix. In other words it defines the electron donating power of the oxygen in the oxide glass. The optical basicity can be calculated according to the approach proposed by Duffy and Ingram [10].
Optical basicity =

$\mathrm{X}(\mathrm{BaO}) \mathrm{A}(\mathrm{BaO})+\mathrm{X}\left(\mathrm{B}_{2} \mathrm{O}_{3}\right) \mathrm{A}\left(\mathrm{B}_{2} \mathrm{O}_{3}\right)+\mathrm{X}\left(\mathrm{TeO}_{2}\right) \mathrm{A}\left(\mathrm{TeO}_{2}\right)$

Where $\mathrm{x}(\mathrm{BaO}), \mathrm{x}\left(\mathrm{B}_{2} \mathrm{O}_{3}\right)$ and $\mathrm{x}\left(\mathrm{TeO}_{2}\right)$ are the equivalent fraction of the different oxides ,i.e. the proportion of the oxide atom that contributes to the glass system; $\mathrm{A}(\mathrm{BaO})$, $\mathrm{A}\left(\mathrm{B}_{2} \mathrm{O}_{3}\right)$ and $\mathrm{A}\left(\mathrm{TeO}_{2}\right)$ are the optical basicity values of the constituent oxides. Here values of $\mathrm{A}(\mathrm{BaO})$ is $1.23, \mathrm{~A}\left(\mathrm{~B}_{2} \mathrm{O}_{3}\right)$ is 0.42 and $\mathrm{A}\left(\mathrm{TeO}_{2}\right)$ is 0.96 ,respectively[11]. It is clear from table (2),that the values of optical basicity increase by increasing $\mathrm{BaO}$ content, which means that the studied glasses becomes more basic.

\subsection{The electronic polarizability of oxide ions}

The relationship between electronic polarizability of oxide ions and optical basicity of oxide is given by this equation [11]

\section{Electronic polarizability of oxide ion =}

\subsection{7/ (1.67-optical basicity)}

This equation indicates that, the Electronic polarizability of oxide ion increase with increasing the optical basicity [12]. The values of electronic polarizability of oxide ions are listed in Table [2]. It was found that all the studied glasses become more polarized by increasing $\mathrm{BaO}$ content for all the studied samples.

Table (1) : The values of molecular weight, density, molar volume, and oxygen packing density for all the studied samples.

\begin{tabular}{|c|c|c|c|c|}
\hline Sample & $\begin{array}{c}\text { Molecular } \\
\text { weight }(\mathrm{g} / \mathrm{mol})\end{array}$ & Density $\left(\mathrm{g} / \mathrm{cm}^{3}\right)$ & $\begin{array}{c}\text { Molar } \\
\text { volume }\left(\mathrm{V}_{\mathrm{m}}\right) \\
\left(\mathrm{cm}^{3} / \mathrm{mol}\right)\end{array}$ & $\begin{array}{c}\text { Oxygen } \\
\text { packing } \\
\text { density }\end{array}$ \\
\hline$\left[\left(\mathrm{TeO}_{2}\right) 0_{\cdot 7}\left(\mathrm{~B}_{2} \mathrm{O}_{3}\right)_{0.3}\right]_{50}(\mathrm{BaO})_{50}$ & 142.968 & 5.110 & 27.978 & 58.974 \\
\hline$\left[\left(\mathrm{TeO}_{2}\right) 0_{.7}\left(\mathrm{~B}_{2} \mathrm{O}_{3}\right)_{0.3}\right]_{40}(\mathrm{BaO})_{60}$ & 145.040 & 5.214 & 27.817 & 54.643 \\
\hline$\left[\left(\mathrm{TeO}_{2}\right) 0_{.7}\left(\mathrm{~B}_{2} \mathrm{O}_{3}\right)_{0.3}\right]_{30}(\mathrm{BaO})_{70}$ & 147.113 & 5.312 & 27.694 & 50.191 \\
\hline
\end{tabular}

Table (2) : The values of optical basicity, oxide ion polarizability, and average single bond strength of all the studied samples.

\begin{tabular}{|c|c|c|c|}
\hline sample & $\begin{array}{c}\text { Optical } \\
\text { basicity }\end{array}$ & $\begin{array}{c}\text { Oxide ion } \\
\text { polarizability } \\
\left(\mathrm{A}^{0}\right)^{3}\end{array}$ & $\begin{array}{c}\text { average single bond } \\
\text { strength }(\mathrm{KJ} / \mathrm{mol})\end{array}$ \\
\hline$\left[\left(\mathrm{TeO}_{2}\right) 0_{.7}\left(\mathrm{~B}_{2} \mathrm{O}_{3}\right)_{0.3}\right]_{50}(\mathrm{BaO})_{50}$ & 1.014 & 2.546 & 216.45 \\
\hline$\left[\left(\mathrm{TeO}_{2}\right) 0_{.7}\left(\mathrm{~B}_{2} \mathrm{O}_{3}\right)_{0.3}\right]_{40}(\mathrm{BaO})_{60}$ & 1.057 & 2.724 & 189.96 \\
\hline$\left[\left(\mathrm{TeO}_{2}\right) 0_{.7}\left(\mathrm{~B}_{2} \mathrm{O}_{3}\right)_{0.3}\right]_{30}(\mathrm{BaO})_{70}$ & 1.100 & 2.930 & 163.47 \\
\hline
\end{tabular}




\subsection{Average single bond strength:}

The high polarizability of oxide ions leads to stronger chemical bonds [12].The average single bond strength $\mathrm{B}_{\mathrm{M}-\mathrm{O}}$ has been determined by the following equation [12].

$$
\mathbf{B}_{\mathrm{M}-\mathrm{O}}=\mathbf{x}_{\mathrm{BaO}} \mathbf{B}_{\mathrm{Ba}-\mathrm{O}}+\mathbf{x}_{\mathrm{TeO} 2} \mathbf{B}_{\mathrm{Te}-\mathrm{O}}+\mathbf{x}_{\mathrm{B} 2 \mathrm{O} 3} \mathbf{B}_{\mathrm{B}-\mathrm{O}}
$$

Where, $\mathrm{x}_{\mathrm{BaO}}, \mathrm{x}_{\mathrm{B} 2 \mathrm{O} 3}$ and $\mathrm{X}_{\mathrm{TeO} 2}$ is the molar fraction. The single bond strength of $\mathrm{Ba}-\mathrm{O}, \mathrm{B}-$ $\mathrm{O}$ and $\mathrm{Te}-\mathrm{O}$ are $(84,498$ and $285 \mathrm{KJ} / \mathrm{mol})$, respectively [11].

The values of average single bond strength for all the studied samples are listed in table (2). It is clear that the values of average single bond strength decrease by increasing $\mathrm{BaO}$ content. This can account by considering the bond strength of $\mathrm{BaO}$ which is lower than other bonds.

\subsection{Optical energy gap:}

Figure (1) shows the optical transmission spectra for all the studied samples. The absorption coefficient $\alpha$ of each sample was calculated using the relation [13].

$$
\alpha=(1 / d) \ln \left(I_{0} / I_{t}\right)
$$

Where $\mathrm{I}_{0}$ and $\mathrm{I}_{\mathrm{t}}$ are the intensity of the incident and transmitted radiation, respectively and $\mathrm{d}$ is the thickness of the sample. Mott and Davis [13] proposed the relation between the absorption coefficient $\alpha(\omega)$ and the photon energy $\hbar \omega$ of the incident radiation, for indirect transitions this relation can be written as follows,

$$
\alpha \hbar \omega=\beta\left(\hbar \omega-E_{\text {opt }}\right)^{2}
$$

Where $\omega$ is the angular frequency of radiation, $\beta$ is constant called band parameter, $\mathrm{E}_{\mathrm{opt}}$ is the optical energy gap. The proposed absorption mechanism is indirect one. This is expected due to the lack of translate symmetry, where the wave vector is not good quantum number. The values of $E_{\text {opt }}$ is obtained by plotting $(\alpha \hbar \omega)^{1 / 2}$ vs photon energy $\hbar \omega$ and extrapolating the linear region of the plots to $(\alpha \hbar \omega)^{1 / 2}=0$. This extrapolated value is the optical energy gap of thin film as shown in Figure (2). The obtained values of $\mathrm{E}_{\mathrm{opt}}$ for all the studied glasses are given in Table [3]. It is clear that, the value of optical band gap energy decrease by increasing $\mathrm{BaO}$ content as a result of decreasing the average single bond strength for all the studied samples. The weaker bond strength of $\mathrm{Ba}-\mathrm{O}$ $(84 \mathrm{KJ} / \mathrm{mol})$ compared to $\mathrm{Te}-\mathrm{O}(285 \mathrm{KJ} / \mathrm{mol})$, and $\mathrm{B}-\mathrm{O}(373 \mathrm{KJ} / \mathrm{mol}$ are responsible for the decrease of optical energy gap enegy[15].

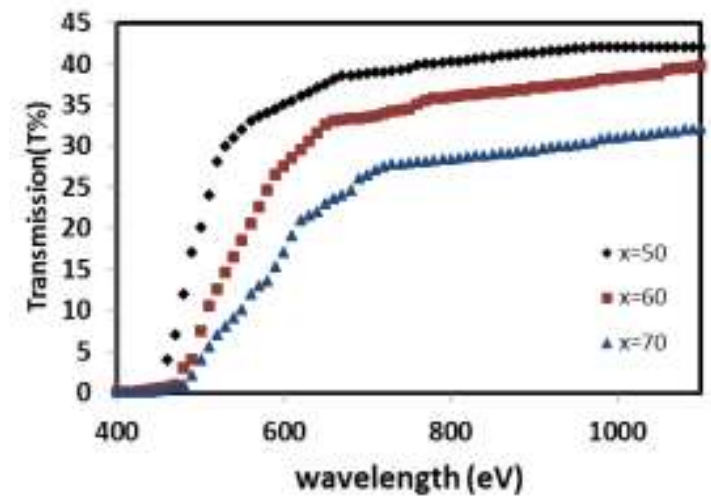

Figure (1) : The transmission spectra for all the studied samples.

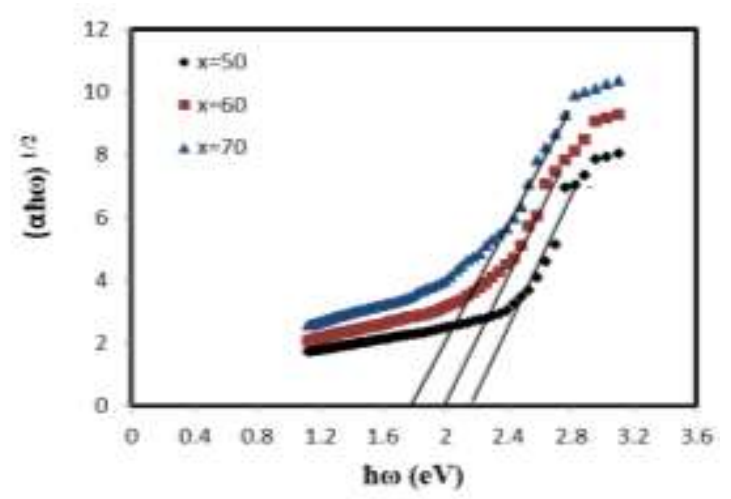

Figure (2): The relation between $\hbar \omega$ and $(\alpha \hbar \omega)^{1 / 2}$ for all the studied samples.

\subsection{The molar refraction:}

The molar refraction can be calculated as follows [12]:

$$
R_{m}=V_{m}\left(1-\left(E_{o p t} / 20\right)^{1 / 2}\right)
$$

It was found that the values of molar refraction which are listed in table (3) increase by increasing $\mathrm{BaO}$ content.

\subsection{The refractive index:}

The calculation of the refractive index is very important to determine the suitability of 
Table (3): The values of optical energy gap, refractive index, molar refraction, third order nonlinear susceptibility and metallization of all the studied samples.

\begin{tabular}{|c|c|c|c|c|c|}
\hline Sample & $\begin{array}{c}\text { optical energy } \\
\text { gap }(\mathrm{eV})\end{array}$ & $\begin{array}{c}\text { Molar refraction } \\
\mathrm{R}_{\mathrm{m}}\left(\mathrm{cm}^{3} / \mathrm{mol}\right)\end{array}$ & $\begin{array}{c}\text { Refractive } \\
\text { index }\end{array}$ & $\begin{array}{c}\text { Third order nonlinear } \\
\text { susceptibility } \\
\chi^{3} \times 10^{-12} \text { esu. }\end{array}$ & metallization \\
\hline$\left[\left(\mathrm{TeO}_{2}\right) 0_{.7}\left(\mathrm{~B}_{2} \mathrm{O}_{3}\right)_{0.3}\right]_{50}(\mathrm{BaO})_{50}$ & 2.20 & 18.699 & 2.654 & 5.361 & 0.332 \\
\hline$\left[\left(\mathrm{TeO}_{2}\right) 0_{\cdot 7}\left(\mathrm{~B}_{2} \mathrm{O}_{3}\right)_{0.3}\right]_{40}(\mathrm{BaO})_{60}$ & 2.00 & 19.020 & 2.736 & 7.110 & 0.316 \\
\hline$\left[\left(\mathrm{TeO}_{2}\right) 0_{\cdot 7}\left(\mathrm{~B}_{2} \mathrm{O}_{3}\right)_{0.3}\right]_{30}(\mathrm{BaO})_{70}$ & 1.80 & 19.386 & 2.828 & 9.635 & 0.300 \\
\hline
\end{tabular}

glass material to be optical devices [14]. The linear refractive index, $n$, can be calculated [12] as follows,

$$
\mathbf{n}=\left(\left(V_{m}+2 R_{m}\right) /\left(V_{m}-R_{m}\right)\right)^{1 / 2}
$$

The values of refractive index are listed in table (3). It was found that the values of the refractive index increase by increasing $\mathrm{BaO}$ content. The refractive index depends on the polorazibility of glass material [14] .The values of refractive index increase because the values of molar polorazibility increase by increasing $\mathrm{BaO}$ content for all the studied samples.

\subsection{Metallization criterion of the glasses:}

Dimitrov and Sakka [12] calculated metallization criterion for various simple oxides and found that oxides with large refractive index and small energy gap have small metallization criterion linked to small refractive index and large energy gap.

\section{The metallization criterion $=\left[\mathrm{E}_{\mathrm{opt}} / \mathbf{2 0}\right]^{1 / 2}$}

The values of metallization criterion for all the studied samples are listed in table (3).It was found that the metallization criterion values of the present glasses are found to be less than one and thus all the studied samples exhibit insulating behavior [12] .Also, it was found that the values of metallization decrease by increasing $\mathrm{BaO}$ because the values of optical energy gap decrease for all the studied samples.

\subsection{Third order nonlinear susceptibility:}

The high polarizability of oxide ions accounts to the perceived nonlinear optical properties of the glasses. The glasses with greater nonlinear optical properties, especially third order nonlinear susceptibility, are appropriate to produce nonlinear waveguide devices lawful to optical signal processing [15]. The third order nonlinear susceptibility in esu units is calculated by the following relation [15],

$$
\left.\chi^{(3)}=\left((\mathrm{n})^{2}-1\right) / 4 \pi\right)^{4} \times 10^{-10}
$$

From table (4), it was found that the values of third order nonlinear optical susceptibility increase by increasing $\mathrm{BaO}$ content because the values of the refractive index increase for all the studied samples. Because of the high values of third order nonlinear optical susceptibility for all the studied samples, these glasses are perhaps good materials for nonlinear optical applications [12].

\section{CONCLUSION:}

From all the above arguments, it was found that the values of density, refractive index, increase by increasing $\mathrm{BaO}$ content. On the other hand, the values of average single bond strength, optical energy gap, decrease by increasing $\mathrm{BaO}$ content. Also, all the studied samples become more basic and more polarized and all the studied samples exhibit insulating behavior by increasing $\mathrm{BaO}$ content. The high values of third order nonlinear optical susceptibility for all the studied samples were found to be in the range (5.361-9.635) $\times 10^{-}$ ${ }^{12}$ esu. Finally, all the above values are a good basis for suggestion new nonlinear optical materials.

\section{REFERENCES:}

[1]T. R. Tasheva* and V. V. Dimitrov ,Synthesis, structure and nonlinear optical properties of tellurium oxide - bismuth oxide - boron oxide 
glasses , Bulgarian Chemical Communications, 49(2017)43.

[2] T. Tashva, V. Dimitrov, Synthesis, optical properties and structure of $\mathrm{NiO} \mathrm{BaO} \quad \mathrm{V}_{2} \mathrm{O}_{5}$ glasses., J. of Chem. Tech. and Metallargy, 52(2017)369.

[3] G. S. Murugan, Y. Ohishi, $\mathrm{TeO}_{2}-\mathrm{BaO}-\mathrm{SrO}-$ $\mathrm{Nb}_{2} \mathrm{O}_{5}$ glasses:a new glass system for waveguide devices applications, $\mathrm{j}$ of Non Cryst. Solids,341(2004)86.

[4] S.E. Ibrahim ,Y.S. Ramnal ,I.Z. Hager ,R. El Mallawany, Uv and electrical properties of $\mathrm{TeO}_{2}-\mathrm{WO}_{3} \mathrm{LiO}-\mathrm{Nb}_{2} \mathrm{O}_{5} / \mathrm{Sm}_{2} \mathrm{O}_{3} / \mathrm{Pr}_{6} \mathrm{O}_{11} / \mathrm{ErO}_{3}$ glasses, J. of Non Crystalline Solids ,498(2018)443.

[5] F.M .Fudzi ,H.M. Kamari ,F.D. Muhamad ,A.A. Latif ,Z. Ismail Structural and optical properties of Zinc Borotellurite glass Co dopped with Lanthanum and silver oxide , J. of Material Science and Chemical Engineering 6(2018)18.

[6] D. Ehrt, Structure, properties and applications of borate glasses, Glass Technology , 41(2000)182.

[7] K. Singh, H. Singh, G. Sharma, R. Nathuram, A. Khanna, R. Kumar, S. S. Bhatti, H. S. Sahota, Phys. Chem. Glasses, 43(2002) 5.

[8] R. El-Mallawany, Tellurite Glasses Handbook; CRC Press Inc, Boca Raton, FL, USA, (2002).

[9] K. J. Singh, S. Kaur and R. S. Kaundal , Radiation Physics and Chemistry, 96 (2014) 153.

[10] J.A. Duffy and M.D. Ingram, "Optical properties of glasses," , the American Ceramic Society (1991) P 159.

[11] V. Dimitrov and S. Sakka, Electronic oxide polarizability and optical basicity of simple oxides. ,J. Appl. Phys. 79(1996) 1736.

[12] V. Dimitrov and T. Komatsu, "An interpretation of optical properties of oxide and oxide glasses in terms of the electronic ion polarizability and average single bond strength, J. of University of Chemical Techology and Metallurgy, 43(2010) 219.

[13] N.F.Mott ,E.A.Davis ,Electronic processes in non crystalline materials, Oxford university press ,Oxford, 1979.

[14] M.N. Azlan ,M.K. Hlimah ,S.Z. Shafinas , W.M. D"Polarizability and optical basicity of
$\mathrm{Er}^{3+}$ ions doped tellurite based glasses", Chalcogenide letters, 11(2014) 319.

[15] T. Tashera and V. Dimitrov, "Optical properties and structure of $\mathrm{B}_{2} \mathrm{O}_{3} \mathrm{BaOV}_{2} \mathrm{O}_{5}$ Glasses.", J. of Chemical Technology and Metallurgy, 50 (2015) 441. 